\title{
Dr. Dorfman legacy to pathology: beyond Rosai-Dorfman disease
}

\author{
Maria Claudia Nogueira Zerbinia
}

Zerbini MCN. Dr. Dorfman legacy to pathology: beyond Rosai-Dorfman disease [editorial]. Autopsy Case Rep [Internet]. 2013;3(1): 1-4. http://dx.doi.org/10.4322/acr.2013.001

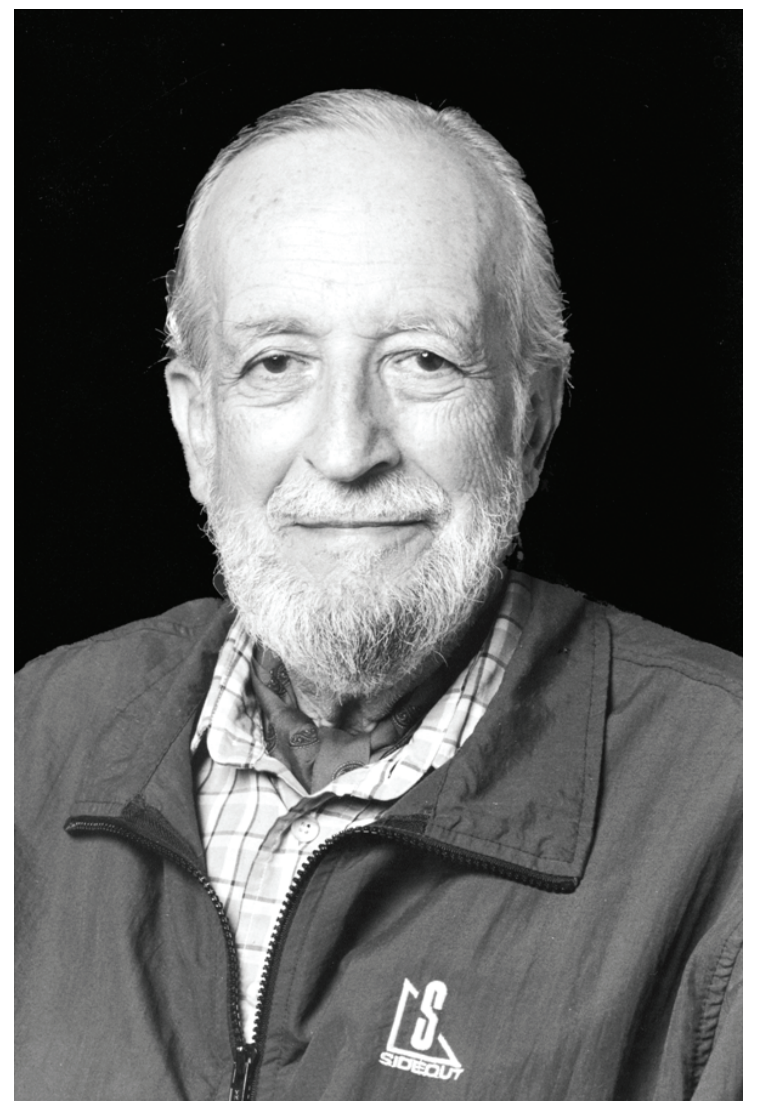

Credit to Stanford School of Medicine.

Ronald F. Dorfman (1923-2012), an Emeritus Professor of Pathology at the Stanford University School of Medicine, had significant input in advancing the study of diseases of hematopoietic cells and the lymph nodes, which included identifying a disease that has been named after him. Dr. Dorfman was one of the founders of the field of Hematopathology, and, with Dr. Costan Berard, founded the Society of Hematopathology in 1981, serving as its president from 1982 through 1984, and published a classification of non-Hodgkin lymphomas in $1974,{ }^{1}$ which was a variant of the Rappaport classification. ${ }^{2}$
Dr. Dorfman was born in Johannesburg, South Africa, on March 14, 1923 and studied medicine at the University of the Witwatersrand. From 1944 to 1946 his medical studies were suspended due to his military service during World War II. In 1948, he received his medical degree and completed medical and surgical internships and residencies at the Johannesburg General Hospital. After that, he went to England, to obtain his MD in Internal Medicine at the Royal Postgraduate Medical School and Hammersmith Hospital. At one point, he concluded that clinical medicine was not his passion

${ }^{a}$ Department of Pathology - Faculdade de Medicina - Universidade de São Paulo, São Paulo/SP - Brazil.

Copyright $\odot 2013$ Autopsy and Case Reports - This is an Open Access article distributed of terms of the Creative Commons Attribution NonCommercial License (http://creativecommons.org/licenses/by/3.0/) which permits unrestricted non-commercial use, distribution, and reproduction in any médium provided article is properly cited. 
and switched to pathology, initially in London and subsequently at the South African Institute for Medical Research (SAIMR) in Johannesburg. During his nine years of working there, his interest in the lymphoreticular system was stimulated by Dr. George Oettlé, who was the head of the South African National Cancer Institute at that time.

During the early 1960s at the SAIMR, Dr. Dorfman came across two very unusual cases. The patients were African boys, aged 9 and 19, presenting enlarged lymph nodes in the neck, producing a "bullneck" appearance. The oldest patient's disease had started 10 years earlier, and the disease followed a stable course. The histological appearance was so uncommon that the slides were submitted to several consultants in England, including Dr. Alistair Robb-Smith at Oxford University and Professor Donald Harrison at the Postgraduate Medical School of London. Varied opinions included "an unusual reaction to an undetermined infectious agent," a cholesterol-type lipidosis, and even a form of Letterer-Siwe disease. In a fascinating article published recently by Dr. Dorfman in a periodical of the Adler Museum of Medicine, University of the Witwatersrand, Johannesburg, he described in detail the identification of this rare and intriguing disease. $^{3}$

In 1963, due to his opposition to a society that established the superiority of white races over the black people of South Africa, he immigrated with his family to St. Louis, Missouri, USA, as Assistant Professor in the Surgical Pathology Division of the Department of Pathology at the Washington University School of Medicine, invited by Dr. Lauren V. Ackerman. While working there, one day a surgical pathology fellow named Juan Rosai, born in Poppi, Italy, came to his office with slides of two peculiar cases, which he identified among a series of cases he had been studying, including lymph node biopsies with the diagnosis of "malignant reticuloendotheliosis" - a generic term embracing malignant disorders of the socalled reticuloendothelial system. The patients were a boy and a girl, both 7 months old presenting enlarged painless cervical lymph nodes. The two doctors studied the slides of these cases as well as those from Dr. Dorfman's two patients from Johannesburg, and immediately agreed that they were dealing with the same disease. Reviewing the literature, Dr. Rosai found two more cases with great clinical and histological similarities to theirs. ${ }^{4,5}$ They prepared and submitted the first description of the entity they named "sinus histiocytosis with massive lymphadenopathy (SHML): a newly recognized benign clinicopathologic entity". ${ }^{6}$

The publication stimulated a great deal of interest and by the end of 1971 they had collected 30 new cases received in consultation, motivating their second paper with detailed analysis of their 34 cases, establishing the validity of SHML as a definitive clinicopathologic entity. ${ }^{7}$ They described the histological features in early and advanced phases of the disease, and called attention to the most conspicuous feature, seen in greater or lesser degree in every case: the presence of apparently viable hematopoietic cells (mostly lymphocytes) within extremely large cells, with abundant, clear, granular or finely vacuolated cytoplasm and large, round, vesicular nuclei containing distinct nucleoli. Later, histochemical and immunophenotypic studies were able to support these large cells as having the features of histiocytes and activated monocytes/ macrophages. ${ }^{8}$ They differed from reactive sinus histiocytes by virtue of their strong staining for $S 100$ protein. In addition, they differed from Langerhans cell histiocytes in that they failed to express CD1a antigen, and they do not have Birbeck's granules at the electron microscopy. The other peculiar finding was the presence of dozens of lymphocytes located within cytoplasmic vacuoles, which most probably represented the ability of these cells to enter and leave the histiocytic cytoplasm without undergoing degenerative changes, a phenomenon known as emperipolesis (from the Greek: em = inside, peri $=$ around, polesis $=$ going about $)$. They further emphasized the essentially benign nature of the disease and the capacity of this disorder to clinically simulate a malignant process.

It was in 1973 that a group of Spaniards published a paper using the eponym Rosai-Dorfman for the first time, and from that time this name was adopted by many others, particularly for those cases where the disease was exclusively extranodal. ${ }^{9}$

Dr. Rosai, who had been appointed Head of Anatomic Pathology at Yale University in New Haven, Connecticut, USA, created an archive of all the cases of SHML he was aware of, first at Minnesota and after at Yale. As an increasing number of cases were sent to Dr. Rosai and Dr. Dorfman in consultation over the ensuing years, they began to appreciate that SHML affected not only lymph nodes but also many different extranodal sites, at times without lymph node involvement. The most prominent extranodal manifestations were observed in the skin and soft tissues, upper 
respiratory tract, bone, genitourinary system, lower respiratory tract, and oral cavity, but nowadays the literature has shown that this disease can occur anywhere.

In 1990, the editor of Seminars in Diagnostic Pathology decided to devote an entire issue of the journal to a review of the clinical and pathological features of 423 cases of extranodal SHML. ${ }^{10}$

Nowadays, the cause of Rosai-Dorfman disease is still unknown. It is suspected that it may be of viral etiology and that minor upper respiratory tract infections may stimulate the characteristic interaction between lymphocytes, the unique histiocytes and plasma cells, resulting in massive lymphadenopathy and the widespread extranodal lesions of this disorder. There is no specific treatment for Rosai-Dorfman disease and the lesions are not responsive to antibiotics. Treatment is not necessary in most cases and enlarged lymph nodes usually resolve spontaneously; however, some patients may require surgery, radiation therapy and/or chemotherapy because of severe disease manifestations.

A month before his death, Dr. Dorfman went to the Stanford Department of Pathology to give his opinion on an unusually difficult example of RosaiDorfman disease. I wondered what comments he would make about the challenging case of SHML presented in this issue of Autopsy and Case Reports. As in this case, a series of 14 deaths occurring in the SHML registry were described, and it was noted that many of these patients had had immunologic and/or hematologic abnormalities. ${ }^{11,12}$

"Ron Dorfman was considered a gifted diagnostician, teacher, and researcher, but those who knew him well were equally impressed by his warmth. He was considered a consummate gentleman and scholar." These were the words of Dr. Stacey E. Mills, Editor-in-Chief of The American Journal of Surgical Pathology at the time of Dr. Dorfman's death last June.

Beyond the enigmatic disease of RosaiDorfman, we hope that this brief overview of $\mathrm{Dr}$. Dorfman's life can inspire many young pathologists around the world to be good observers, to seek the answers to their questions, and to practice medicine with humanity and passion.

\section{ACKNOWLEDGEMENTS}

The author thanks to Prof. Juan Rosai for reviewing the text.

\section{REFERENCES}

1. Berard CW, Dorfman RF. Histopathology of malignant Iymphomas. Clin Haematol. 1974;3(1):39-76. http://dx.doi. org/10.1016/S0308-2261(74)80005-6

2. Rappaport H. Tumors of the hematopoietic system. Washington: Armed Forces Institute of Pathology; 1966. (Atlas of Tumor Pathology).

3. Dorfman RF. The true story behind Rosai-Dorfman disease. Adler Mus Bull. 2008;34(1):13-8. PMid:20050417.

4. Azoury FJ, Reed RJ. Histiocytosi. Report of an anusual case. New Engl J Med. 1966;274(17):928-30. PMid:5908885. http://dx.doi.org/10.1056/NEJM196604282741702

5. Vincent TN, Miercort R, editor. Case 9. Eighteenth Seminar of the Penrose Cancer Hospital. 1967;3:246-50.

6. Rosai J, Dorfman RF. Sinus histiocytosis with massive lymphadenopathy - a Newly recognized benign clinicopathological entity. Arch Pathol. 1969;87(1):63-70. PMid:5782438.

7. Rosai J, Dorfman RF. Sinus histiocytosis with massive lymphadenopathy: a pseudolymphomatous benign disorder. Analysis of 34 cases. Cancer. 1972;30(5):1174-88. http:// dx.doi.org/10.1002/1097-0142(197211)30:5<1174::AIDCNCR2820300507>3.0.CO;2-S

8. Eisen RN, Buckley PJ, Rosai J. Immunophenotypic characterization of sinus histiocytosis with massive lymphadenopathy (Rosai-Dorfman disease). Semin Diagn Pathol. 1990;7(1):74-82. PMid:2180014.

9. Vallé Jiménez AFGJ, Martinez Martinez A. Histiocitosis sinusal con linfadenopatia masiva de Rosai y Dorfman. Patologia. 1973;6:263-7.

10. Foucar E, Rosai J, Dorfman R. Sinus histiocytosis with massive lymphadenopathy (Rosai-Dorfman disease): review of the entity. Semin Diagn Pathol. 1990;7(1):19-73. PMid:2180012.

11. Foucar E, Rosai J, Dorfman RF. Sinus histiocytosis with massive lymphadenopathy. An analysis of 14 deaths occurring in a patient registry. Cancer. 1984;54(9):1834-40. http:// dx.doi.org/10.1002/1097-0142(19841101)54:9<1834::AIDCNCR2820540911>3.0.CO;2-F

12. Foucar E, Rosai J, Dorfman RF, Eyman JM. Immunologic abnormalities and their significance in sinus histiocytosis with massive lymphadenopathy. Am J Clin Pathol. 1984;82(5):515-25. PMid:6496400. 
Correspondence: Maria Claudia Nogueira Zerbini

Editor in Chief Autopsy and Case Reports

Hospital Universitário - Universidade de São Paulo, São Paulo/SP - Brazil

E-mail: czerbini@usp.br 